\title{
Arsitektur sebagai Media Interaksi Manusia dan Hewan
}

\author{
Sayid Rasyid Ridha dan Endy Yudho Prasetyo \\ Departemen Arsitektur, Fakultas Arsitektur, Desain dan Perencanaan \\ Institut Teknologi Sepuluh Nopember (ITS) \\ e-mail: endy_yudho_prasetyo@arch.its.ac.id
}

\begin{abstract}
Abstrak-Keinginan untuk terhubung dengan alam merupakan salah satu sifat alami yang dimiliki oleh manusia. Namun, seiring dengan berkembangnya wilayah urban, alam yang berada di sekitar manusia mulai tergantikan oleh pe mukiman manusia. Hal ini menyebabkan semakin berkurangnya habitat bagi makhluk hidup lainnya, salah satunya adalah hewan. Akibatnya, munculah suatu fenomena yang disebut dengan synanthropization, yaitu masuknya hewan ke dalam lingkungan manusia untuk beradaptasi dengan habitat manusia tersebut. Keberadaan hewan-hewan tersebut ada yang dapat ditolerir oleh manusia, namun ada juga yang justru menjadi masalah bagi manusia. Dalam menanggapi fenomena ini, diperlukan adanya desain suatu kawasan di mana manusia dan hewan tadi dapat hidup bersama tanpa adanya rasa ketidaknyamanan diantaran kedua spesies. Kawasan ini didesain untuk menyediakan habitat bersama bagi hewan dan manusia di mana kedua spesies dapat saling berinteraksi, namun di satu sisi tetap memiliki batas-batas tertentu untuk menjaga area privasi masing-masing spesies.
\end{abstract}

Kata Kunci-Synurbanization, Synanthropization, Synanthropic Spaces, Batas, Interaksi, Habitat.

\section{PENDAHULUAN}

SEJAK zaman dahulu, pada kesehariannya alam merupakan S suatu aspek yang tidak dapat dipisahkan dari kehidupan manusia. Namun, seiring dengan meningkatnya teknologi dan kemampuan manusia dalam membangun, semakin berkurang juga integrasi yang terjadi antara manusia dan aspek alam tersebut. Akibat maraknya pembangunan ini, banyak aspek natural environment yang menjadi habitat dari makhluk hidup lain dari manusia yang mulai hilang dan tergantikan oleh built environment yang diciptakan manusia. Hal ini memaksa makhluk hidup lain - dalam konteks ini, hewan- untuk bermigrasi dari tempat tersebut atau beradaptasi dengan lingkungan manusia tersebut. Dengan adanya proses adaptasi dengan built environment milik manusia tersebut munculah suatu fenomena yang disebut dengan Synurbanization dan Synanthropization.

Synurbanization merupakan suatu fenomena di mana hewan masuk ke dalam lingkungan perkotaan karena kecocokan terhadap lingkungan kota, sementara Synanthropization mengacu pada populasi hewan yang beradaptasidi lingkungan manusia sementara [1].

Di Indonesia, fenomena synurbanization dan synanthropization kerap dianggap sebagai hal yang negatif di mana keberadaan hewan liar sering dianggap sebagai penganggu yang merusak barang milik warga, seperti hasil kebun dan hasil ternak.

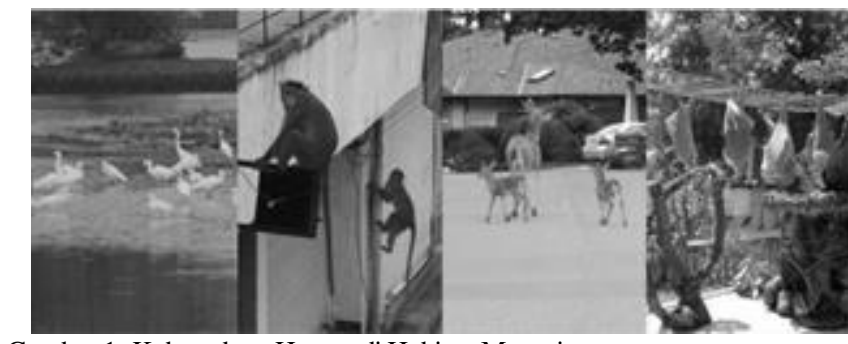

Gambar 1. Keberadaan Hewan di Habit at Manusia.

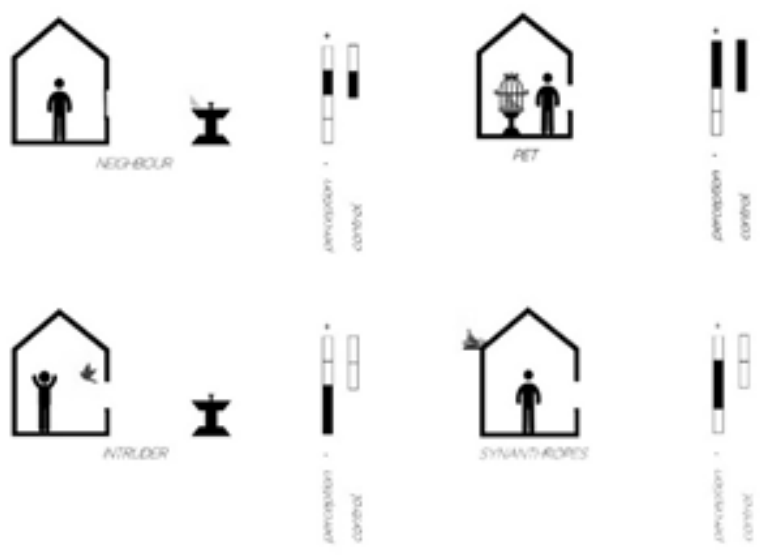

Gambar 2. Pengaruh Batas Terhadap Persepsi Manusia.

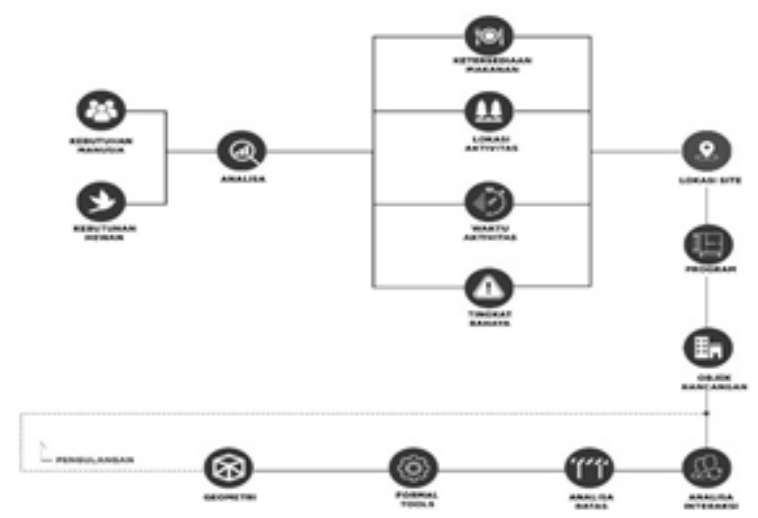

Gambar 3. Metoda Kebutuhan Hewan dan Manusia.

Untuk menanggapi isu ini, penulis merasa dibutuhkannya sebuah objek rancangan di mana bisa memfasilitasi kehidupan dari manusia dan hewan di mana kedua makhluk hidup ini dapat hidup dengan nyaman pada objek rancangan ini dan tidak saling terganggu akan keberadaan satu dengan lainnya. 


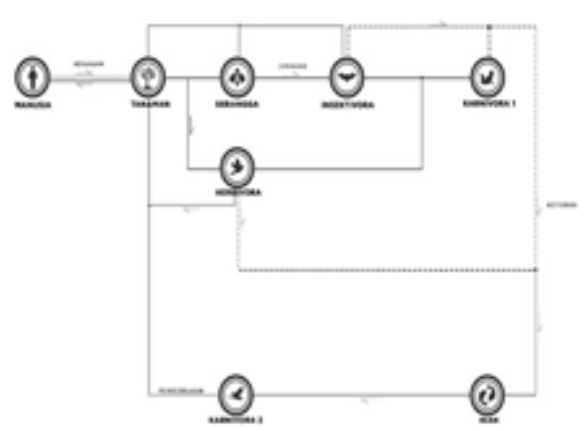

Gambar 4. Metoda Siklus pada Objek Rancangan.

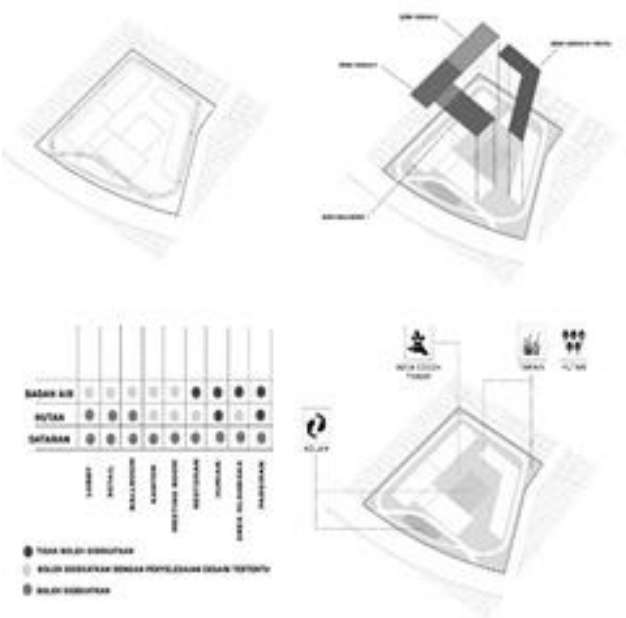

Gambar 5. Perletakan Zonasi Hewan dan Program Manusia.

Rasa nyaman atau tidak nyaman tersebut dapat timbul dari persepsiakan masing-masing makhluk hidup yang mana salah satunya dapat dipengaruhi dengan batas yang memisahkan antara keduanya (Gambar 2) [2]. Selain itu, rasa nyaman tersebut dapat berkembang seiring dengan semakin tingginya intensitas interaksi yang terjadi di antara keduanya. Oleh karena itu, objek rancangan ini nantinya juga harus menjadi sebuah media di mana manusia dapat berinteraksi dengan hewan sehingga konsep kohabitasi dapat terlaksana dengan baik, namun di satu sisi dapat tetap menjaga batas -batas privasi dari kedua makhluk hidup ini.Sebagai tipologi bangunan, penulis memilih untuk merancang sebuah kawasan hunian vertikal dikarenakan hunian merupakan salah satu tipologi yang mana privasi tiap penghuninya harus sangat terjaga sehingga menimbulkan tantangan lebih dalam merancang konsep batas dan interaksi yang akan terjadi pada objek rancangan.

\section{EKSPLORASI DAN PROSES RANCANG}

Dalam proses eksplorasi objek rancang ini penulis menggunakan dua macam metoda. Metoda pertama adalah dengan menganalisa kebutuhan-kebutuhan yang dimiliki oleh hewan dan manusia. Kebutuhan kebutuhan yang dimaksud di sini berkaitan dengan lokasi ketersediaan makanan, lokasi aktivitas, waktu aktivitas dan juga tingkat bahaya yang akan ditimbulkan jika kedua makhluk tersebut diletakkan bersama. Metoda ini nantinya akan menghasilkan kriteria lahan yang akan menjadi wadah dari objek rancangan, tipologi objek rancangan, serta program apa saja yang dibutuhkan pada objek

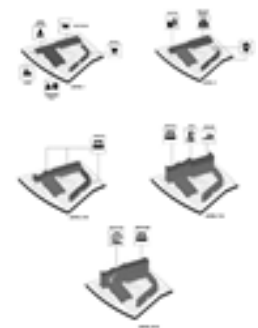

Gambar 6. Program Aktivitas Manusia.

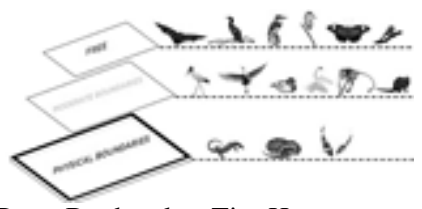

Gambar 7. Konsep Batas Berdasarkan Tipe Hewan.
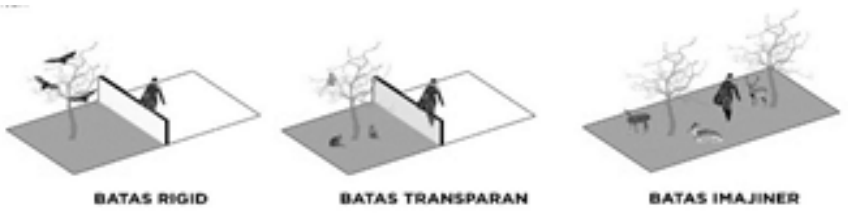

Gambar 8. Konsep Batas Berdasarkan Interaksi.

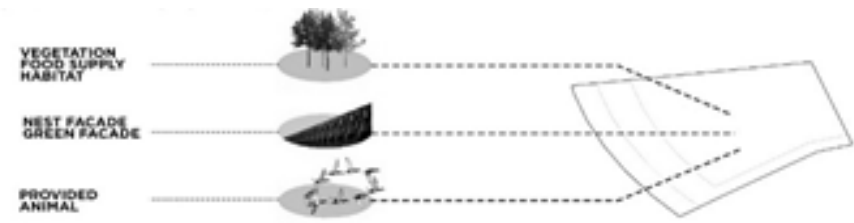

Gambar 9. Konsep Attractor Hewan.

rancangan natinya, serta perletakan masing-masing program (Gambar 3) .

Metoda selanjutnya yang digunakan berhubungan dengan siklus. Siklus hubungan interaksi antara hewan

dan hewan dengan tumbuhan sebenranya sudah terjadi secara alami di alam liar. Pada objek rancangan ini, penulis mencoba memasukkan manusia sebagai bagian dari siklus tersebut. Hal ini dapat dituju dengan menyediakan area media tanam pada objek rancangan sehingga manusia bisa ikut menjadi factor yang menyediakan makanan bagi hewan. Dengan adanya hal ini, diharapakan terdapatnya intensitas interaksi yang terjadi di antara manusia dan hewan tersebut (Gambar 4).

Kedua metoda tersebut nanitnya menjadi parameter untuk perletakkan zonasi dan program pada objek rancangan (Gambar 5). Berdasarkan metoda pertama tadi, didapatkanlah zonasizonasi yang kira-kira dibutuhkan oleh hewan, yaitu zona badan air, zona dataran atau rerumputan serta zona pepohonan. Selain itu, dibutuhkan juga program yang diperuntukkan sebagai shelter dari hewan nantinya. Ketiga zonasi tersebut nantinya diletakkan di lahan, berdasarkan parameter dari luar lahan, seperti keberadaan jalan, sungai, pepohonan dan bangunan dan beberapa parameter lainnya. Setelah itu, ditetapkanlah program-program manusia apa saja yang akan dimasukkan pada objek rancangan (Gambar 6) [3], lalu zonasi hewan dan program manusia tadi disusun dalam sebuah matriks untuk mengetahui program apa saja yang dapat diletakkan berdekatan dengan zonasi hewan tertentu. 
wonsep ranph
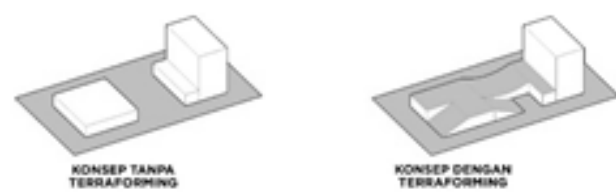

Gambar 10. Konsep Terraforming.

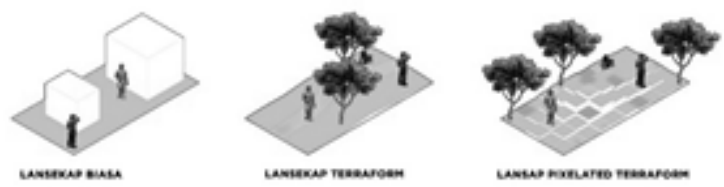

Gambar 11. Konsep Pixelated Terraforming.

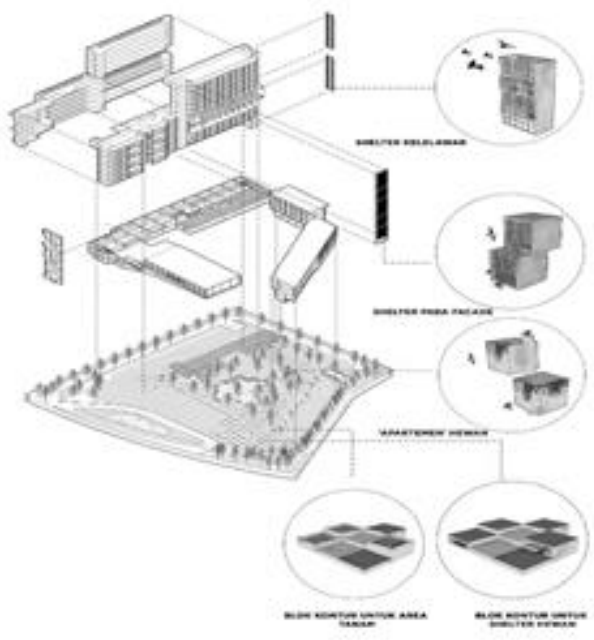

Gambar 12. Konsep Shelter Hewan.
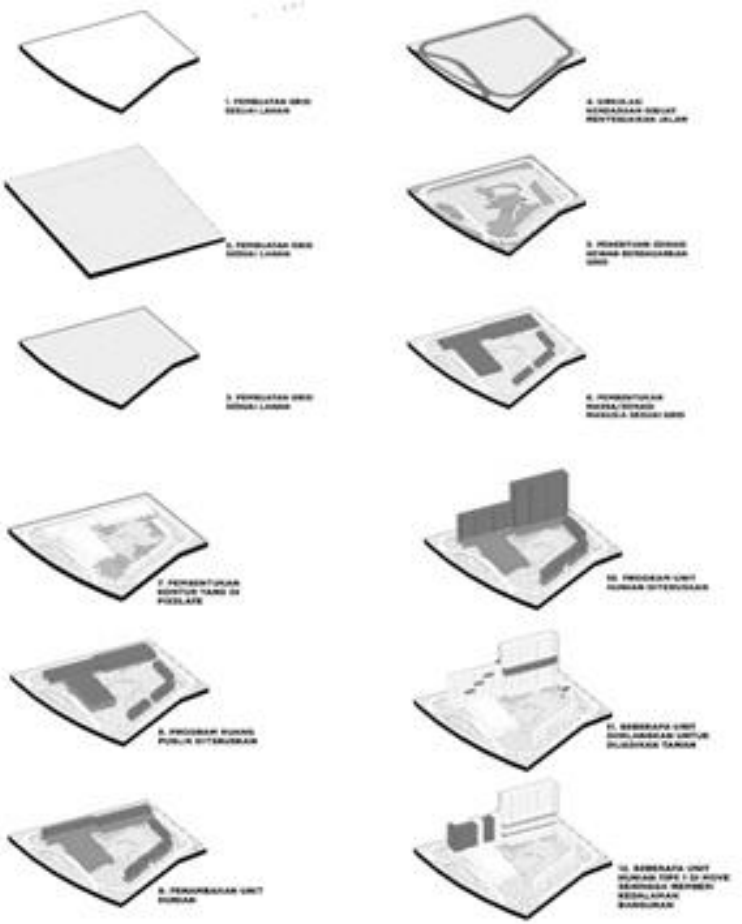

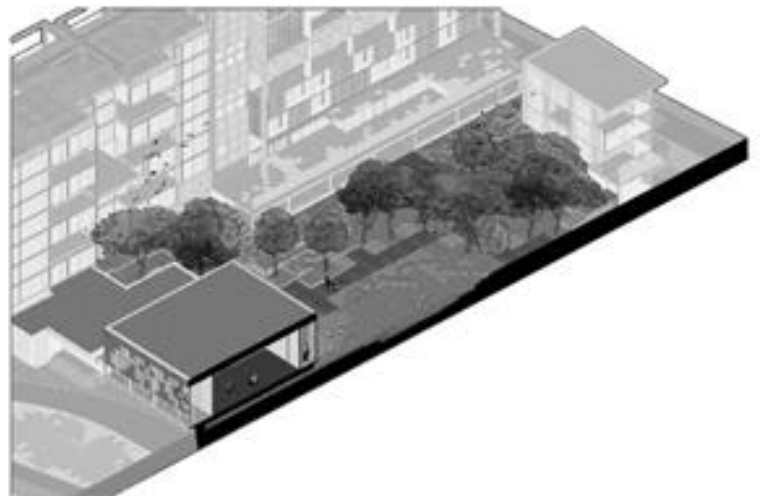

Gambar 14. Aksonometri Taman.

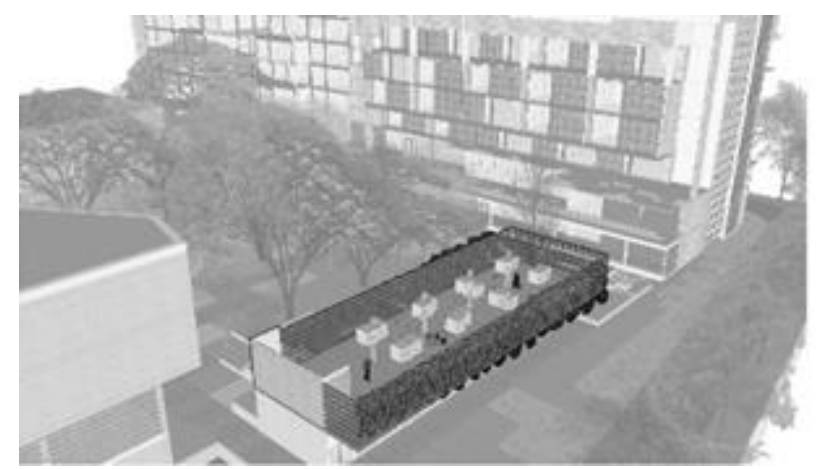

Gambar 15. Aksonometri Shelter Hewan.

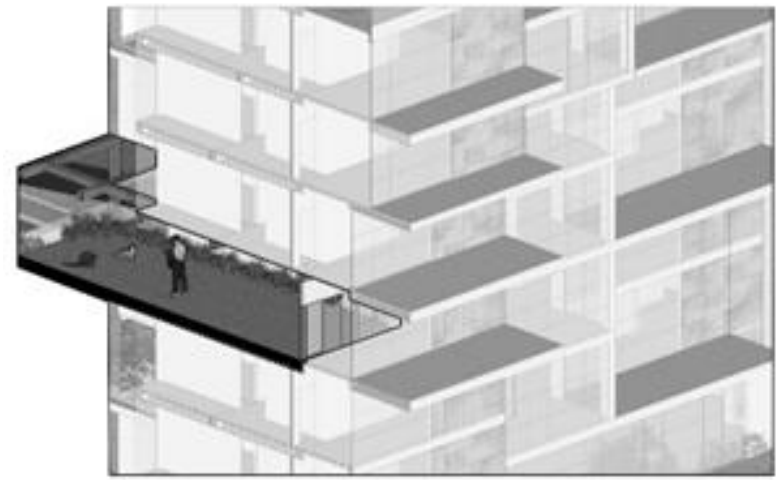

Gambar 16. Aksonometri Teras.

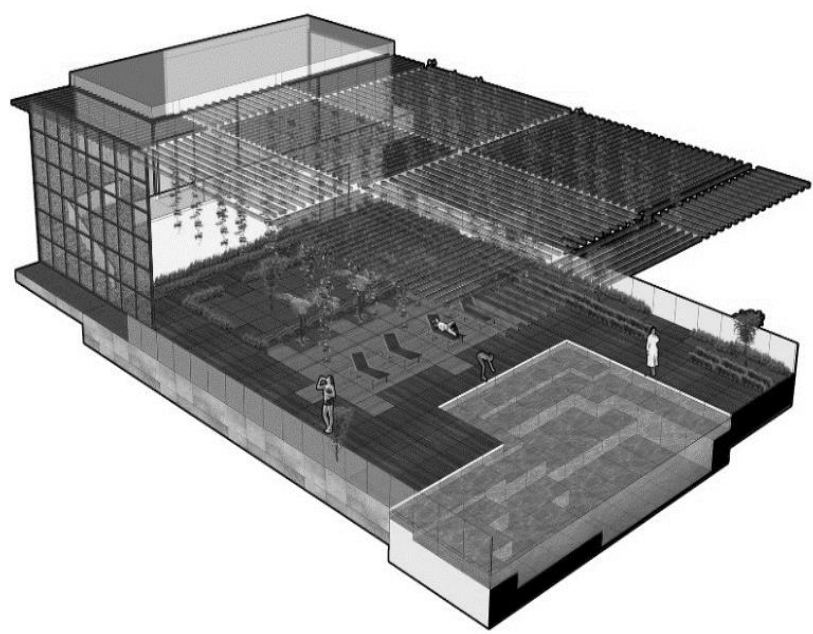

Gambar 17. Aksonometri Taman Gnatung pada SArana Olahraga. 


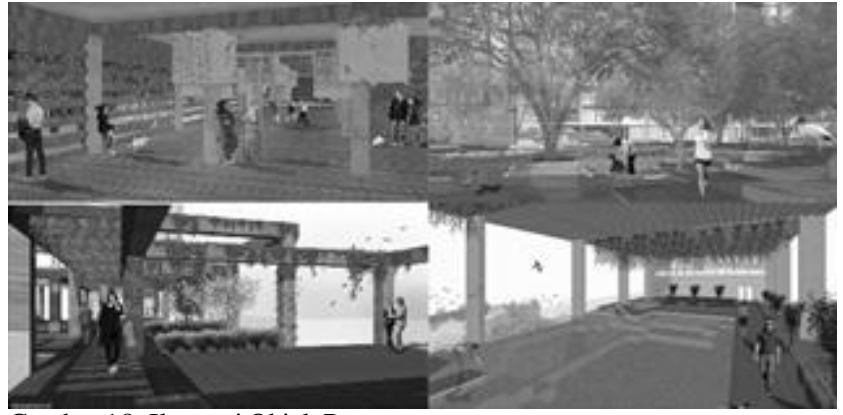

Gambar 18. Ilustrasi Objek Rancangan.

Dari metoda-metoda ini, nantinya barulah dilakukan transformasi bentuk yang juga disesuaikan dengan konsepkonsep yang akan diterapkan pada objek rancangan nantinya.

\section{HASIL RANCANGAN}

Selain penggunaan metoda yang dijelaskan pada BAB II, dalam merancang objek rancangan ini diperlukan beberapa konsep yang membentuk segala aspek seperti massa, lansekap dan berbagai aspek lainnya. Dalam objek rancangan ini diterapkan beberapa konsep yaitu;

2.1 Konsep Batas Sesuai Tipe Hewan (Gambar 7)

Konsep batas ini muncul berdas arkan tipe-tipe hewan apa saja yang ingin dipikat untuk masuk ke objek rancangan dan hewan apa saja yang harus di tahan agar tidak masuk ke dalam objek rancangan. Berdasarkan tipe hewan ini, batas yang akan dirancangn anntinya terbagi menjadi tiga macam, yaitu batas bebas (free boundaries), batas menegah (moderate boundaries) dan batas fisik(physical boundaries). Batas bebas diterapkan pada area di mana hewan dapat mengaksesnya secara bebas. Batas menegah diterapkan pada area di mana sebagian hewan saja yang dapat memasukinya sementara batas fisik diterapkan pada area di mana memang hewan tidak bis a memasukinya sama sekali.

2.2 Konsep Batas Sesuai Interaksi (Gambar 8)

Batas ini muncul sesuai dengan interaksi antara manusia-hewan seperti apa yang diinginkan pada objek rancangan. Batas-batas ini terbagi menjadi batas rigid, batas transparan dan batas imajiner. Batas fisik diterapkan pada kawasan dimana interaksi yang terjadi sangat minim. Interaksi di sini lebih berupa interaksi secara audio. Batas transparan merupakan batas pada kawasan di mana interaksi yang terjadi merupakan interaksi secara visual. Batas imajiner adalah batas yang diterapkan pada kawasan di mana interaksi yang terjadi lebih luas. Interaksi yang dimaksudkan bis a berupa interaksi audio, visual dan juga secara langsung. Rasa akan aman atau tidak nyaman terhadap hewan pun sudah bergantung kepada persepsi individu.

2.3 Konsep Atrractor Hewan (Gambar 9)

Agar hewan hewan yang diinginkan menetapi kawasan objek rancangan diperlukan adanya faktor faktor yang diperlukan untuk memenuhi kebutuhan hewan hewan tersebut. Hal ini berfungsi sebagai pemicu agar hewan yang berada di sekitar objek rancangan tertarik untuk ikut bermukim pada area objek rancang. Attractor hewan ini antara lain berupa Penyediaan supply makanan bagi hewan, penyediaan shelter di mana hewan tersebut bermukim atau bersarang, serta menyediakan beberapa jenis hewan tertentu untukmemancing hewan-hewan liar di sekitar objek rancang untuk masuk ke dalam objek rancang.

2.4 Konsep Terraforming dan Pixelated Terraforming (Gambar 10)

Terraforming merupakan suatu cara untuk menggabungkan antara lansekap dan bangunan. Dengan adanya terraforming, area yang dapat dieksplorasi oleh hewan dan manusia dapat lebih bebas dibandingkan ketika tidak ada terraforming, dikarenakan batas vertikal dan horizontal dapat dianggap melebur.

Namun, kelemahan dari sistem terraforming ini adalah sisi sisi dari kontur yang sebenarnya dapat lebih dimanfaatkan sebagai shelter bagi hewan hewan. Konsep pixelated yang digabungkan dengan terraforming membentuk bentukan sepertin kontur namun dengan sisi sisi yang dapat dimanfaatkan sebagaisuatu ruang. Bagian atas kontur pixelated ini pun dapat digunakan sebagai media tanam bagi penghuniobjek rancangan. (Gambar 11)

Selain 4 konsep di atas, pada objek rancangan nantinya juga akan disediakan shelter-shelter di mana hewan dapat bermukim atau bersarang (Gambar 12). Dari konsep-konsep tersebut barulah desain dari objek rancangan dapat dirancang,baik massa bangunan, lansekap dan elemen-elemen lainnya (Gambar 13).

Objek rancangan ini sendiri dirancang agar interaksi yang terjadi dapat terjadi bukan di satu titik saja. Selain kawasan taman (Gambar 14) dan shelter hewan (Gambar 15) yang menjadi lokasi utama, pada area unit hunian pun terdapat beberapa taman pada balkon-balkon (Gambar 16) yang dapat diakses oleh hewan dan manusia. Konsep taman gantung pun juga diterapkan pada area sarana olahraga seperti gym dan kolam renang (Gambar 17)(Gambar 18).

\section{KESIMPULAN}

Pembangunan yang dilakukan oleh manusia menjadi salah satu penyebab berkurangnya natural environment yang ada di sekitar kita. Hilangnya natural environment tersebut menjadi salah satu alasan hilangnya habitat yang dimiliki oleh makhluk hidup lain seperti hewan dan tumbuhan.

Dalam berarsitektur, sudah saatnya kita berpikir bahwa bukan hanya kebutuhan manusia lah yang harus dipenuhi. Kita sebagai orang yang menggiati profesi arsitektur juga seharusnya mulai berfikir untur me restorasi alam yang ada di sekitar kita, meskipun restorasi itu terjadi juga dengan menggabungkan desain aristektur dengan aspek alam. 
Hunian Kohabitasi ini merupakan suatu gagasan arsitektur di mana arsitektur yang merupakan aspek kehidupan sehari hari seperti hunian dicoba untuk diintegrasikan dengan alam. Integrasi dengan alam di sini bukan hanya berupa memasukkan unsur unsur alami saja, namun juga dengan mencoba menciptakan habitat baru bagi biota lain yang ada di alam, terutama hewan. Proses yang dilakukan penulis diharapkan dapat menjadi inovasi akan adanya eksplorasi lain di bidang arsitektur yang lebih terintegrasi dengan alam, serta makhluk hidup lain yang ada di sekitar kita.

\section{DAFTAR PUSTAKA}

[1] Monika, "Syburbanization: Integrasi Binatang Dengan Manusia Di Kota," 2014.

[2] S. Gunawan, "Synanthropic Suburbia," University of Waterloo, 2015.

[3] E. Neufert, P. Neufert, B. Baiche, and N. Walliman, Architects'data. Oxford: Blackwell Science, 2000. 